\title{
STRATEGI PENENTUAN LOKASI DAN KEBUTUHAN LAHAN TPS (TEMPAT PENAMPUNGAN SEMENTARA SAMPAH) BERDASARKAN FUNGSI KAWASAN DI KOTA DENPASAR
}

\author{
Ismid Achmad $^{1 *}$, I Made Sudarma ${ }^{1}$, Syamsul Alam Paturusi ${ }^{1}$ \\ ${ }^{1}$ Program Studi Magister Ilmu Lingkungan Universtias Udayana Bali, Jl. PB Sudirman Denpasar Bali \\ *Email : demituang@yahoo.co.id
}

\begin{abstract}
The percentage of solid waste services Denpasar City in 2013 reached 51,8 percent, the limited number and capacity TPS in Denpasar not meet the needs of waste management services in denpasar. The study was to examine the relevant strategies appropriate to the criteria and requirements related to the determination of the location of TPS and the land need. The position of the study is Part Of The City (BWK) Central in Denpasar. Analysis of technical aspects will evaluation garbage production in order to know the ideal needs of TPS, the evaluation of TPS placement based on the function of the area and the land needed. Environmental aspect will analyze the environmental risk due to the presence of a TPS. Analysis of public opinion and the behavior of people will use a questionnaire in the collection of data to be analyzed with qualitative methods as a consideration in determining the location and design of a TPS. Institutional aspect will be evaluated about the understanding DKP (Office of Cleaning and Gardening Services) employees of the City of Denpasar in the management of garbage, especially in the TPS. As for determining the direction and strategy of the management of garbage SWOT analysis was used.Based on the analysis, the need for the addition of TPS to improve the capacity of TPS, the shape of TPS had comply standard of SNI and environmental safety factor. Additions and changes in the shape of TPS also effect land requirement, the total area of land that must be reserved for TPS is 0,40 hectares. Determining the location of TPS is based on the need of the type of TPS over the spatial pattern. Analysis of public opinion on the determination of the location of TPS, it is obtained that the distance of a TPS with the source must be relatively close and the land use is a vacant land. It is also suggested optimizing the role of the DKP of Denpasar by increasing socialization and community development programs in waste management.
\end{abstract}

Keywords : Garbage, TPS, Zone Function, Denpasar

\section{PENDAHULUAN}

Aktivitas manusia tidak terlepas dari kegiatan yang menghasilkan limbah atau sampah baik itu limbah organik maupun non organik. Kota Denpasar adalah salah satu kota yang mengalami pertumbuhan penduduk dan ekonomi yang cukup tinggi sehingga memicu meningkatnya kegiatan di bidang jasa, industri, bisnis dan sebagainya. Salah satu dampak yang dihasilkan adalah meningkatnya produksi limbah buangan atau sampah. Berdasarkan hasil studi Penyusunan Standar Pelayanan Minimal Kota Denpasar tahun 2013 persentase pelayanan persampahan Kota Denpasar tahun 2013 baru mencapai 51,8 persen. Sistem pengumpulan sampah di Kota Denpasar pada umunya menggunakan tempat penampungan sementara (TPS), dimana sampah yang dihasilkan dari setiap rumah dikumpulkan di TPS dan dari TPS selanjutnya diangkut ke TPA.

Jumlah dan kapasitas TPS di Kota Denpasar masih belum memenuhi akan kebutuhan pelayanan sampah di Kota Denpasar. Jumlah dan kapasitas TPS yang terbatas ini dipengaruhi juga oleh keterbatasan lahan untuk penempatan TPS di
Kawasan Pusat Perkotaan. Belum adanya arahan dan strategi yang jelas dalam penentuan lokasi dan sebaran TPS dengan kondisi keterbatasan lahan di wilayah perkotaan dan sulitnya lahan untuk pembangunan TPS yang layak sesuai dengan standar, ini menimbulkan permasalahan yang serius seperti bercecerannya sampah pada TPS yang mengakibatkan menurunnya estetika lingkungan. Kondisi lingkungan perkotaan yang sangat kompleks akan beban pencemaran yang ditimbulkan oleh setiap aktivitas manusia menuntut adanya penataan dan pengelolaan yang baik untuk meminimalkan dampak pencemaran lingkungan.

Perencanaan tata ruang kota yang mengklaisifikasikan fungsi kawasan yang berbedabeda akan mempengaruhi sistem penanganan sampah yang harus dilakukan, hal ini dipengaruhi oleh karakteristik dan volume sampah yang dihasilkan serta ketersediaan lahan pada setiap fungsi kawasan dalam RTRW.Dengan perencanaan sistem pewadahan atau tempat penampungan sampah sementara yang bersinergi dengan RTRW diharapkan dapat memanfaatkan keterbatasan ruang kota dengan maksimal.Pengaturan lokasi TPS menjadi tujuan utama dalam penelitian ini, karena 
saat ini kebutuhan dan sebaran TPS yang tidak seimbang dengan timbulan sampah yang dihasilkan serta lokasi TPS yang diletakan pada tempat yang tidak semestinya, seperti diatas trotoar atau di badan jalan karena keterbatasan lahan di perkotaan. Berdasarkan permasalahan di atas, maka penelitian ini dilakukan untuk menganalisis lokasi dan kebutuhan lahan TPS yang ada di Kota Denpasar dengan syarat dan kriteria teknis serta pertimbangan fungsi kawasan Perkotaan. Diharapkan pada nantinya keberadaan TPS tidak mencemari lingkungan dan memberikan kenyamanan bagi penduduk yang tinggal di sekitar TPS.

\section{METODE}

\subsection{Analisis Aspek Teknis Sebaran dan Kebutuhan Lokasi TPS}

Analisis aspek teknis bertujuan untuk mengevaluasi dan menganalisa pengelolaan sampah di Kota Denpasar khususnya pada lokasi TPS, analisis dilakukan dengan cara membandingkan antara kondisi eksisting dengan standar pada SNI dan rencana tata ruang kota Denpasar. Langkah Langkah dalam analisis teknis ini meliputi :

1. Mengevaluasi timbulan sampah di wilayah studi, hal ini dilakukan untuk membandingkan antara kapasitas TPS dengan sampah yang dihasilkan oleh penduduk.

2. Mengevaluasi lokasi TPS, hal ini bertujuan untuk mengetahui radius pelayanan TPS di suatu kawasan.

3. Menganalisis dan mengevaluasi penempatan TPS berdasarkan fungsi kawasan perkotaan.

4. Mengevaluasi kebutuhan lahan untuk masingmasing jenis TPS, hal ini terkait dengan kebutuhan lahan yang dibutuhkan untuk menyediakan TPS di suatu kawasan.

5. Mengevaluasi kebutuhan TPS di suatu kawasan, dilakukan berdasarkan radius pelayanannya.

\subsection{Analisis Aspek Lingkungan Terkait Lokasi TPS}

Analisis aspek lingkungan ini dilakukan agar mengetahui resiko yang mungkin terjadi akibat adanya kegiatan penampungan sampah di TPS. Metoda yang digunakan adalah analisis kualitatif, analisis kualitatif ini menampilkan matriks antara suatu kegiatan dengan resiko kerusakan lingkungan yang mungkin akan terjadi. Matriks dalam analisis kualitatif ini terdiri dari matriks analisis peluang dan matriks analisis besarnya resiko. Proses akhir analisis ini adalah dengan cara mengkombinasikan bobot yang ada pada matriks peluang dan matriks besaran resiko, jika hasil dari kombinasi tersebut menunjukkan resiko rendah dan tidak merusak estetika kota maka TPS ini dinyatakan aman bagi kelestarian lingkungan. Penentuan nilai peluang dan nilai resiko dihitung berdasarkan menggunakan kuesioner yang disebarkan kepada masyarakat, instansi pengelola persampahan, pakar dibidang persampahan dan praktisi bidang lingkungan.

Tabel 1. Contoh Penilaian Resiko Metoda Analisis Kualitatif Penentuan Lokasi TPS

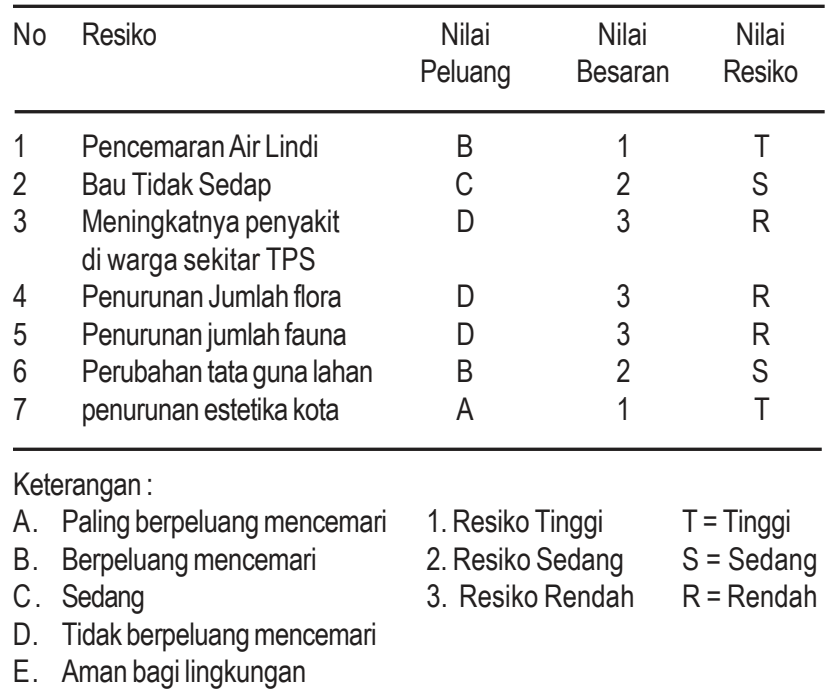

Evaluasi aspek lingkungan juga memperhatikan keberadaan TPS terhadap estetika kota, hal yang tidak kalah pentingnya adalah kenyamanan hunian di permukiman tersebut, oleh karena itu TPS yang dibangun hendaknya memenuhi ketentuan perancangan kota yang baik. Evaluasi TPS berdasarkan konsep perancangan kota menggunakan analisis tapak, analisis ini merupakan salah satu cara untuk melihat keterkaitan antara fisik buatan dengan fisik alamiah.

Tabel 2.2. Kondisi Ideal TPS Terhadap Faktor - faktor Analisis Tapak

\begin{tabular}{lccccc}
\hline $\begin{array}{l}\text { Faktor } \\
\text { Analisis } \\
\text { Tapak }\end{array}$ & $\begin{array}{c}\text { Kejelasan } \\
\text { Lokasi }\end{array}$ & $\begin{array}{c}\text { Sirkulasi } \\
\text { Kendaraan }\end{array}$ & $\begin{array}{c}\text { Sirkulasi } \\
\text { Pejalan } \\
\text { Kaki }\end{array}$ & Angin & $\begin{array}{c}\text { Zona } \\
\text { Kebisingan }\end{array}$ \\
Jenis \\
TPS
\end{tabular}

Seluruh jenis TPS harus memiliki kejelasan lokasi yang dipetakan di setiap kecamatan, kejelasan lokasi TPS ini harus sejalan dengan pola ruang yang ada dalam RTRW. Seluruh jenis TPS harus memenuhi syarat tidak mengganggu sirkulasi kendaraan dan pejalan kaki, serta harus mempertimbangkan arah hembusan angin dan memiliki zona penyangga kebisingan. 
2.3. Analisis Pendapat Masyarakat Tentang Kriteria Penentuan Lokasi TPS di Kota Denpasar

Analisis pendapat masyarakat tentang kriteria penentuan lokasi TPS ini terdiri dari tiga kriteria penentuan lokasi TPS yaitu :

1. Pendapat masyarakat tentang kriteria jarak TPS terhadap timbulan sampah. Kriteria yang disampaikan kepada responden untuk dipilih adalah:
a. $0 \mathrm{~s} / \mathrm{d} 250 \mathrm{~m}$
b. $251 \mathrm{~m} \mathrm{~s} / \mathrm{d} 500 \mathrm{~m}$
c. $501 \mathrm{~m} \mathrm{~s} / \mathrm{d} 750 \mathrm{~m}$
d. $751 \mathrm{~m} \mathrm{~s} / \mathrm{d} 1 \mathrm{~km}$
e. $>1 \mathrm{~km}$

2. Pendapat masyarakat tentang kriteria jarak TPS terhadap rute pengangkutan sampah. Kriteria yang disampaikan kepada responden untuk dipilih adalah:
a. $0 \mathrm{~s} / \mathrm{d} 50 \mathrm{~m}$
b. $51 \mathrm{~m} \mathrm{~s} / \mathrm{d} 100 \mathrm{~m}$
c. $101 \mathrm{~m} \mathrm{~s} / \mathrm{d} 150 \mathrm{~m}$

3. Kriteria masyarakat tentang kriteria penggunaan lahan lokasi TPS.
a. Tanah kosong
b. Sawah, kebun, tegalan
c. Pemukiman, perumahan
d. Perkantoran, perdagangan dan jasa
e. Hutan, belukar

\subsection{Analisis Pendapat Masyarakat Tentang Kriteria Penentuan Lokasi TPS di Kota Denpasar}

Proses Analisis Pola Perilaku masyarakat akan diawali dengan penggalian informasi - informasi, dalam proses observasi peneliti melakukan wawancara yang bersifat mendalam untuk memperoleh makna yang utuh dari sebuah informasi dan mengambil dokumentasi terhadap kondisi yang terkait dengan informasi yang diberikan oleh informan atau narasumber. Metode yang digunakan dalam analisis pola perilaku masyarakat ini adalah metode deskriptif. analisis perilaku masyarakat ini untuk memberikan gambaran tentang:

- Deskripsi bentuk perilaku masyarakat dalam mengelola sampah khusnya pada TPS.

- Deskripsi faktor pembentuk perilaku masyarakat dalam mengelola sampah khususnya pada TPS.

Setelah mengetahui bentuk dan faktor pembentuk perilaku masyarakat dalam mengelola sampah akan dianalisis interakasi hubungan bentuk dan faktor pembentuk perilaku masyarakat dalam mengelola sampah khususnya pada TPS.

\subsection{Analisis Aspek Kelembagaan Pengelola Persampahan}

Analisis kelembagaan ini adalah untuk mengevaluasi kinerja dari institusi yang mengelola persampahan dalam hal ini adalah Dinas Persampahan, Pertamanan dan Kota Denpasar. Analisis ini dilakukan untuk mengevaluasi faktor yang menghambat institusi dalam melakukan penanganan sampah di Kota Denpasar, faktor penghambat tersebut dapat berasal dari internal dan eksternal, antara lain:

a. Faktor penghambat internal meliputi:

- Kurangnya kualitas dan kuantitas sumber daya manusia pada institusi pengelola persampahan.

- Kurangnya pengawasan terhadap pekerja di lapangan.

- Kurangnya pemahaman terhadap tugas pokok dan fungsi institusi.

b. Faktor penghambat eksternal meliputi:

- Aturan atau kebijakan yang tidak mendukung program penanganan sampah di Kota Denpasar.

- Terbatasnya aset yang dimiliki oleh institusi.

Data yang digunakan untuk analisis kelembagaan ini menggunakan data primer yang diperoleh dengan cara menyebarkan kuesioner pada instansi terkait, wawancara dan pengamatan langsung di lapangan. Informasi yang diperoleh dari kuisioner akan diberi skor sesuai dengan banyaknya jawaban yang diperoleh untuk satu jawaban. Jawaban terbanyak akan diolah menjadi variabelvariabel yang akan menentukan permasalahan utama di dalam institusi yang menangani persampahan.

\subsection{Analisis SWOT}

Analisis SWOT ini secara sederhana dapat diartikan sebagai upaya untuk mengetahui kekuatan dan kelemahan sendiri atau memahami setiap potensi dan permasalahan yang ada di suatu wilayah. Faktor kekuatan dan kelemahan merupakan faktor internal sedangkan peluang dan ancaman merupakan faktor eskternal yang dihadapi oleh organisasi/instansi, hasil dari analisis SWOT ini pada akhirnya dapat dijadikan bahan pertimbangan para pemangku kepentingan di daerah untuk mengambil keputusan yang tepat agar daerahnya berkembang sesuai dengan yang direncanakan.

\section{HASIL DAN PEMBAHASAN}

\subsection{Gambaran Umum Wilayah Studi}

Wilayah Studi pada penelitian ini berdasarkan pembagian pola ruang pada RTRW Kota Denpasar yaitu BWK Tengah, dimana wilayah administrasi dan fungsi kawasan pada wilayah penelitian berdasarkan RTRW Kota Denpasar adalah sebagai berikut :

a. Sub BWK Tengah I mencakup Desa Dauh Puri Kangin, Kelurahan Dangin Puri, sebagian Desa Dangin Puri Kauh dan sebagian Desa Dauh Puri Kaja yang berfungsi sebagaiCathus Patha Agung Kota, pusat perdagangan kota, pusat pemerintahan kota dan pusat pelayanan sosial budaya kota; 
b. Sub BWK Tengah II mencakup Sebagian Desa Dauh Puri Kaja, sebagian Desa Pemecutan Kaja, sebagian Kelurahan Pemecutan dan sebagian Desa Pemecutan Klod yang berfungsi sebagai pusat kegiatan pemerintahan kota, pusat permukiman dan pusat perdagangan dan jasa;

c. Sub BWK Tengah III mencakup Desa Dangin Puri Kaja, sebagian Desa Dangin Puri Kauh, Desa Dangin Puri Kangin dan Desa Sumerta Kauh yang berfungsi sebagai pusat permukiman dan pusat perdagangan dan jasa, pendidikan, dan kegiatan olah raga;

d. Sub BWK Tengah IV mencakup sebagian Desa Dangin Puri Klod dan Desa Sumerta Klod yang berfungsi sebagai Pusat Permukiman, Pendidikan, pusat perdagangan dan jasa dan pusat pemerintahan Provinsi Bali; dan

e. Sub BWK Tengah V mencakup Kelurahan Dauh Puri, Desa Dauh Puri Kelod dan Desa Dauh Puri Kauh yang berfungsi sebagai pusat permukiman, perdagangan dan jasa, pelayanan kesehatan dan penidikan.

\subsection{Pengelolaan Sampah di Wilayah Studi}

Sistem pengumpulan sampah di Kota Denpasar pada umunya menggunkan TPS yang tersebar di tujuh kecamatan dengan sistem pengumpulan pola indivual (door to door) menggunakan gerobak, pola individual (door ro door) menggunakan colt pick-up atau truk dan pola komunal yang diterapkan pada permukiman tidak teratur dan pasar. Jumlah sarana TPS yang di wilayah penelitian BWK Tengah berjumlah 38 unit, dengan rincian jenis TPS BIN berjumlah 14 unit, TPS container 16 unit dan TPS Transferdepo 6 unit.

\subsection{Analisis Aspek Teknis Sebaran dan Kebutuhan Lokasi TPS}

\subsubsection{Evaluasi Timbulan Sampah Wilayah Studi}

Evaluasi timbulan sampah dilakukan untuk mengetahui jumlah timbulan sampah diwilayah studi. Jumlah timbulan sampah diwilayah studi bergantung dengan banyaknya jumlah penduduk diwilayah studi. Analisis timbulan sampah dilakukan dengan menghitung jumlah dan proyeksi penduduk diwilayah studi. Jumlah penduduk di wilayah studi BWK Tengah pada tahun 2013 adalah 288.970 dan hasil proyeksi 5 tahun mendatang (2019) dengan menggunakan metode Geometrik adalah sebanyak 470.103.

Berdasarkan proyeksi jumlah penduduk, maka dapat dihitung timbulan sampah yang dihasilkan pada wilayah studi Bagian Wilayah Tengah Kota Denpasar pada tahun 2014 mencapai 939,15 m³/hari dan pada tahun 2019 mencapai 1.527, 83 m²/hari.

\subsubsection{Analsis dan Evaluasi Penempatan TPS dengan Rencana Tata Ruang (RTRW) Kota Denpasar}

Pola ruang Kota Denpasar khususnya pada BWK Tengah memiliki berbagai macam fungsi kawasan yang berbeda - beda, dominasi fungsi kawasan di BWK Tengah adalah pemukiman, perdagangan dan jasa, perkantoran atau pemerintahan, dan ruang terbuka hijau. Berdasarkan hasil survei lokasi TPS yang paling banyak terdapat pada kawasan perdagangan dan jasa yaitu $60 \%$, kawasan permukiman sebanyak $20 \%$, kawasan RTH sebanyak $17 \%$ dan kawasan pemerintahan sebanyak $3 \%$.TPS di wilayah studi tersebar di setiap fungsi kawasan atau pola ruang kota denpasar, namun berdasarkan hasil survei pelatakan lokasi TPS di wilayah studi belum terlihat jelas arahan atau kesesuaian dengan pola ruang Kota Denpasar khususnya BWK Tengah.

\subsubsection{Analsis Kapasitas TPS Dengan Volume Timbulan Sampah}

Analisis kapasitas TPS dengan volume timbulan sampah di wilayah studi dilakukan untuk mengetahui kebutuhan TPS di wilayah studi. Kebutuhan TPS di wilayah studi didapatkan dari selisih daya tampung TPS eksiting dengan volume sampah yang dihasilkan di wilayah studi. Daya tampung didapatkan dari TPS BIN adalah $1 \mathrm{~m}^{3}$ (Volume TPS $=1 \mathrm{~m}^{3} \mathrm{x}$ Sampah diangkat $\left.=1 \mathrm{kali}\right)$, TPS Kontainer daya tampung $6 \mathrm{~m}^{3}$ dan TPS Transferdepo $60 \mathrm{~m}^{3}$. Berdasarkan hasil perhitungan maka didapatkan kapaitas atau daya tampung TPS di wilayah studi pada tahun 2014 sebesar $488 \mathrm{~m}^{3}$, sementara timbulan sampah yang dihasilkan di wilayah studi pada tahun 2014 sebesar $984,64 \mathrm{~m}^{3}$.

Berdasarkan hasil perhitungan, selisih kurangnya daya tampung TPS terhadap timbulan sampah yang paling besar berada pada wilayah BWK Tengah II khususnya pada Desa Sumerta Kelod yaitu $70,72 \mathrm{~m}^{3}$. Sedangkan pada wilayah yang TPS masih memiliki daya tampung terhadap timbulan sampah yang dihasilkan oleh penduduk berada pada wilayah BWK Tengah II pada Desa Pemecutan Kelod, BWK Tengah III pada Desa Dangin Puri Kangin dan Desa Dauh Puri Kaja, BWK Tengah IV pada Desa Dangin Puri Kelod dan BWK Tengah V pada Desa Dauh Puri Kelod. Berdasarkan perhitungantersebut, dapat diketahui pada tahun keberapa masing - masing wilayah harus menambah jumlah TPS. Uraian penambahan jumlah dan kapasitas TPS akan diuraikan pada desa yang tidak memiliki kapasitas penampungan sampah paling tinggi dan rendah.

\section{A. Analisis Penambahan Jumlah dan Kapasitas di Desa Sumerta Kelod \\ Volume sampah yang masuk ke TPS pada tahun 2014 di Desa Dauh Puri Kangin sebesar 65,21 m³,}


sedangkan kapasitas tampungan TPS sebesar $6 \mathrm{~m}^{3}$ (1 unit kontainer dengan kapasitas $6 \mathrm{~m}^{3}$ ). Sesuai dengan hal tersebut, di Desa Sumerta Kelod (BWK Tengah IV) pada tahun 2014 sudah tidak mampu menampung sampah yang dihasilkan oleh penduduk. Dimensi TPS BIN Non Permukiman yang diusulkan adalah panjang $\mathrm{x}$ lebar $\mathrm{x}$ tinggi $(1,5 \mathrm{x} 0,5$ x $1 \mathrm{~m}$ ). Lebar TPS yang hanya $0,5 \mathrm{~m}$ tidak akan menghabiskan ruang untuk pejalan kaki, dari segi estetika pun tidak terlihat kotor karena bentuk TPS yang tertutup rapat (Gambar 1). Dimensi TPS BIN Permukiman diusulkan yang sesuai adalah Panjang $\mathrm{x}$ Lebar $\mathrm{x}$ Tinggi $(1 \times 1,5 \mathrm{x} 1 \mathrm{~m})$. TPS tipe BIN permukiman yang diusulkan akan menambah kapasitas TPS menjadi $1,5 \mathrm{~m}^{3}$. Sesuai dengan hasil analisis usulan kebutuhan dan kapasitas TPS di Desa Sumerta Kelod (BWK Tengah IV) pada tahun 2019 dibutuhkan TPS sebanyak 27 unit sedangkan jumlah eksisting sebanyak 1 unit. Maka pada tahun 2019 di Desa Sumerta Kelod (BWK Tengah IV) harus menambah TPS sebanyak 27 unit dengan rincian sebagai berikut :

- TPS tipe BIN (non permukiman) berkapasitas 1 $\mathrm{m}^{3}$ sebanyak 10 unit

- $\quad$ TPS tipe BIN (permukiman) berkapasitas 1,5 $\mathrm{m}^{3}$ sebanyak 12 unit

- TPS tipe Kontainer berkapasitas $6 \mathrm{~m}^{3}$ sebanyak 4 unit

TPS tipe Transferdepo berkapasitas $60 \mathrm{~m}^{3}$ sebanyak 1 unit.

\section{B. Analisis Penambahan Jumlah dan Kapasitas di Desa Pemecutan}

Volume sampah yang masuk ke TPS pada tahun 2019 di Desa Pemecutan sebesar $48,51 \mathrm{~m}^{3}$, sedangkan kapasitas tampungan TPS sebesar $31 \mathrm{~m}^{3}$ ( 1 Unit TPS BIN kapasitas $1 \mathrm{~m}^{3}$ dan 5 unit Kontainer kapasitas $6 \mathrm{~m}^{3}$ ). sesuai dengan hal tersebut maka di Desa Pemecutan (BWK Tengah II) pada tahun 2019

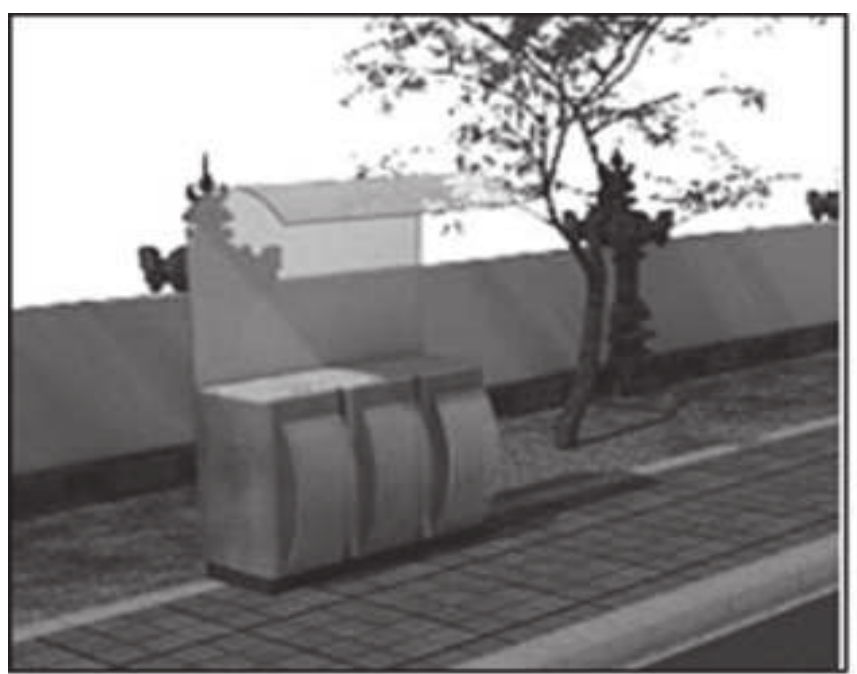

(a) sudah tidak mampu menampung sampah yang dihasilkan oleh penduduk. Dimensi TPS BIN Non Permukiman yang diusulkan adalah panjang $\mathrm{x}$ lebar $\mathrm{x}$ tinggi $(1,5 \times 0,5 \mathrm{x} 1 \mathrm{~m})$. Lebar TPS yang hanya 0,5 $\mathrm{m}$ tidak akan menghabiskan ruang untuk pejalan kaki, dari segi estetika pun tidak terlihat kotor karena bentuk TPS yang tertutup rapat (Gambar 1). Dimensi TPS BIN Permukiman yang diusulkan yang sesuai adalah Panjang $\mathrm{x}$ Lebar $\mathrm{x}$ Tinggi (1 x $1,5 \times 1 \mathrm{~m})$. TPS tipe BIN permukiman yang diusulkan akan menambah kapasitas TPS menjadi $1,5 \mathrm{~m}^{3}$. Sesuai dengan hasil analisis usulan kebutuhan dan kapasitas TPS di Desa Pemecutan (BWK Tengah II) pada tahun 2019 dibutuhkan TPS sebanyak 27 unit sedangkan jumlah eksisting sebanyak 6 unit. Maka pada tahun 2019 di Desa

Tabel 2. Kebutuhan Unit TPS di BWK Tengah Kota Denpasar

\begin{tabular}{llccc}
\hline No Desa / Kelurahan & $\begin{array}{c}\text { Jumlah } \\
\text { TPS } \\
\text { Eksisiting }\end{array}$ & $\begin{array}{c}\text { Kebutuhan } \\
\text { TPS } \\
\text { Ideal 2014 }\end{array}$ & $\begin{array}{c}\text { Kebutuhan } \\
\text { TPS } \\
\text { Ideal 2019 }\end{array}$ \\
\hline 1 Desa Dauh Puri Kangin & 7 & 9 & 17 \\
2 & Kelurahan Dangin Puri & 1 & 14 & 23 \\
3 & Desa Dauh Puri Kaja & 1 & 4 & 15 \\
4 & Desa Pemecutan Kaja & 3 & 20 & 36 \\
5 & Desa Pemecutan & 4 & 8 & 27 \\
6 & Desa Pemecutan Kelod & 5 & 17 & 17 \\
7 & Desa Dangin Puri Kaja & 3 & 22 & 37 \\
8 & Desa Dangin Puri Kauh & 1 & 11 & 19 \\
9 & Desa Dangin Puri Kangin & 1 & 7 & 16 \\
10 & Desa Sumerta Kauh & - & 13 & 26 \\
11 & Desa Dangin Purih Kelod & 2 & 11 & 31 \\
12 & Desa Sumerta Kelod & 2 & 4 & 27 \\
13 & Desa Dauh Puri Kauh & - & 17 & 31 \\
14 & Desa Dauh Puri Kelod & 5 & 17 & 41 \\
15 & Desa Dauh Puri & 1 & 17 & 31 \\
\hline & Jumlah & 36 & 191 & 394 \\
\hline
\end{tabular}

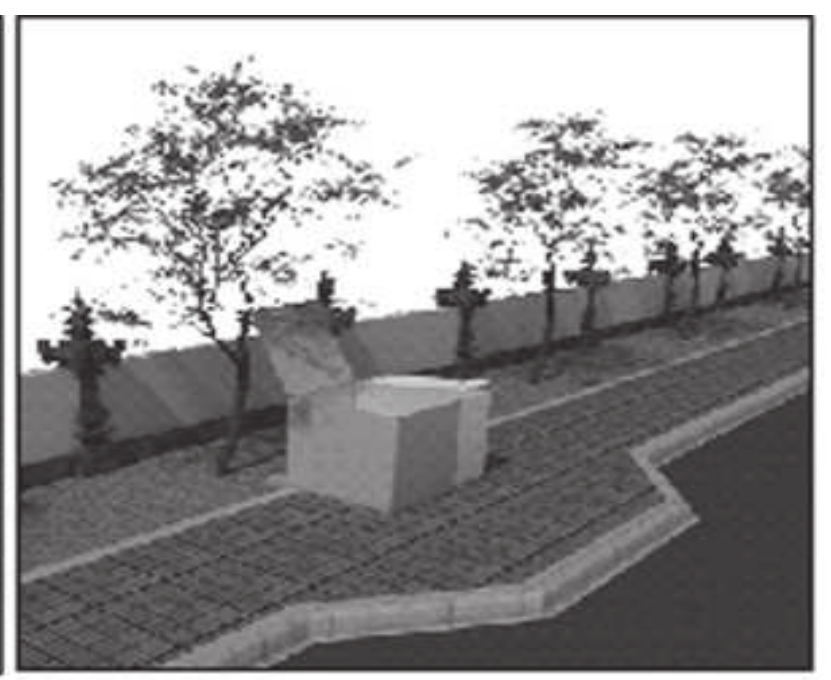

(b)

Gambar 1. (a) Usulan TPS BIN Perkmukiman dan (b)Usulan TPS Non Permukiman 
Pemecutan harus menambah TPS sebanyak 21 unit dengan rincian sebagai berikut :

- TPS tipe BIN (non permukiman) berkapasitas 1 $\mathrm{m}^{3}$ sebanyak 13 unit

- $\quad$ TPS tipe BIN (permukiman) berkapasitas 1,5 $\mathrm{m}^{3}$ sebanyak 10 unit

- $\quad$ TPS tipe Kontainer berkapasitas $6 \mathrm{~m}^{3}$ sebanyak 4 unit

\subsubsection{Analsis Kebutuhan Ruang TPS}

Kebutuhan ruang TPS dihitung berdasarkan hasil analisis dimana adanya perubahan tipikal TPS serta memperhatikan ketentuan SNI yaitu memeperhitungkan dimensi truk pengangkutan, Hasil analisis kebutuhan lahan TPS tanpa memperhitungkan dimensi truk sebesar $946 \mathrm{~m}^{2}$ sedangkan jika memperhitungkan dimensi truk kebutuhan lahan menjadi $7416 \mathrm{~m}^{2}$, selisih luas lahan antara eksisting dengan rencana sebesar $6452 \mathrm{~m}^{2}$ atau setara dengan 0,645 hektar.

\subsubsection{Analsis Penentuan Lokasi TPS}

\section{A. Analisis Kesesuain Lahan TPS}

Hal pertama yang harus diketahui dalam penentuan lokasi TPS adalah menganalisis kesesuain lahan di lokasi penelitian, hal ini dilakukan untuk melihat daya dukung alam untuk menampung kegiatan perkotaan, yakni penggabungan beberapa peta seperti peta topografi dan kemiringan wilayah.

Berdasarkan hasil analisis diketahui seluruh wilayah studi Kota Denpasar BWK Tengah memiliki ketinggian antara 12,5-35 meter diatas permukaan laut, rentang ketinggian tersebut masuk kedalam kategori aman untuk pembangunan kota.

\section{B. Evaluasi Radius Pelayanan TPS}

Radius pelayanan TPS sangat dipengaruhi oleh daya tampung TPS. Semakin besar daya tampung TPS semakin jauh pula pelayananya. Syarat utama dalam penentuan lokasi TPS ini dalah mudah dijangkau oleh masyarakat dan sedekat mungkin dengan sumber sampah. Radius Pelayanan TPS di wilayah studi dapat dilihat pada Gambar 3.

\section{Analisis Aspek Lingkungan Terkait Lokasi TPS \\ 1. Analisis Lingkungan Siktar Lokasi TPS Berdasarkan Tapak Kota}

Analisis tapak terdiri dari empat komponen yang saling terkait, komponen - komponen tersebut memperhitungkan keseimbangan antara kelestaran alam dan kehidupan manusia. Komponen komponen tersebut meleputi kejelasan lokasi, sirkulasi, zona kebisingan dan arah angin. Kondisi TPS yang ada di lapangan sangat beragam, ada yang sudah memenuhi standard dan ada yang belum (Tabel 3).Kondisi TPS sangat mempengaruhi tapak wilayah studi karena jika TPS tersebut kondisinya buruk, maka pada lokasi tapak perlu dipertimbangkan bentuk TPS yang baik agar tidak menganggu kenyamanan penduduk yang menghuni di kawasan permukiman.
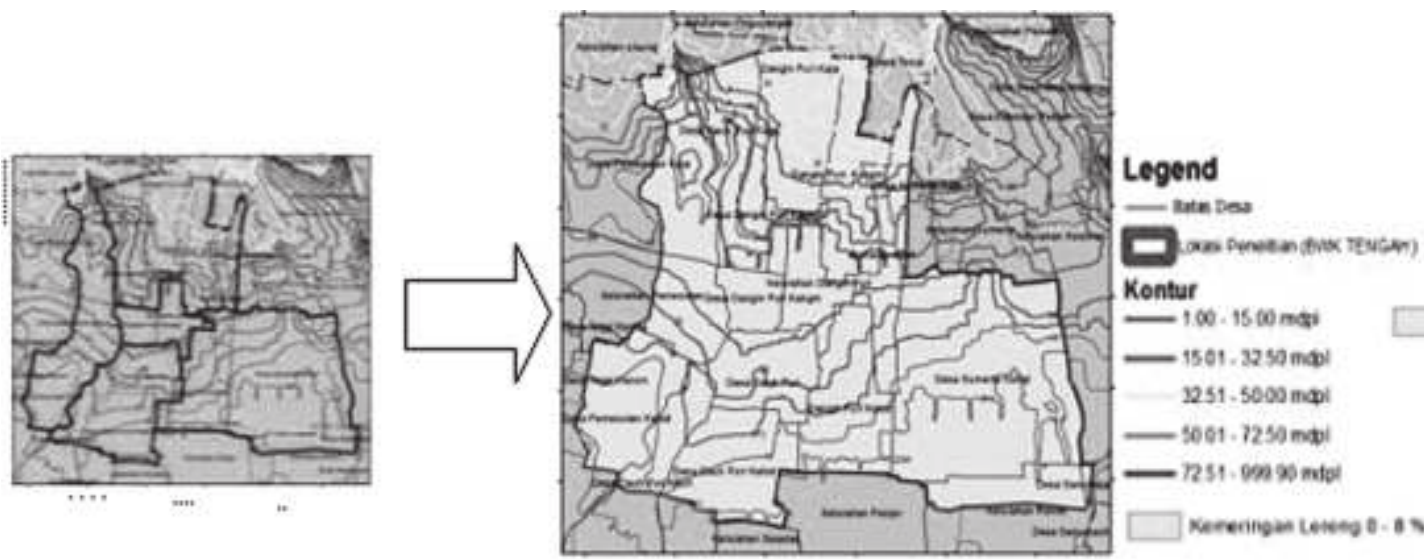

- $100 \cdot 15$. 60 mai

- $1501.3250 \mathrm{mal}$

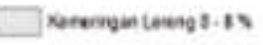

Gambar 2. Overlay Peta Ketinggian dan Kemiringan Wilayah 


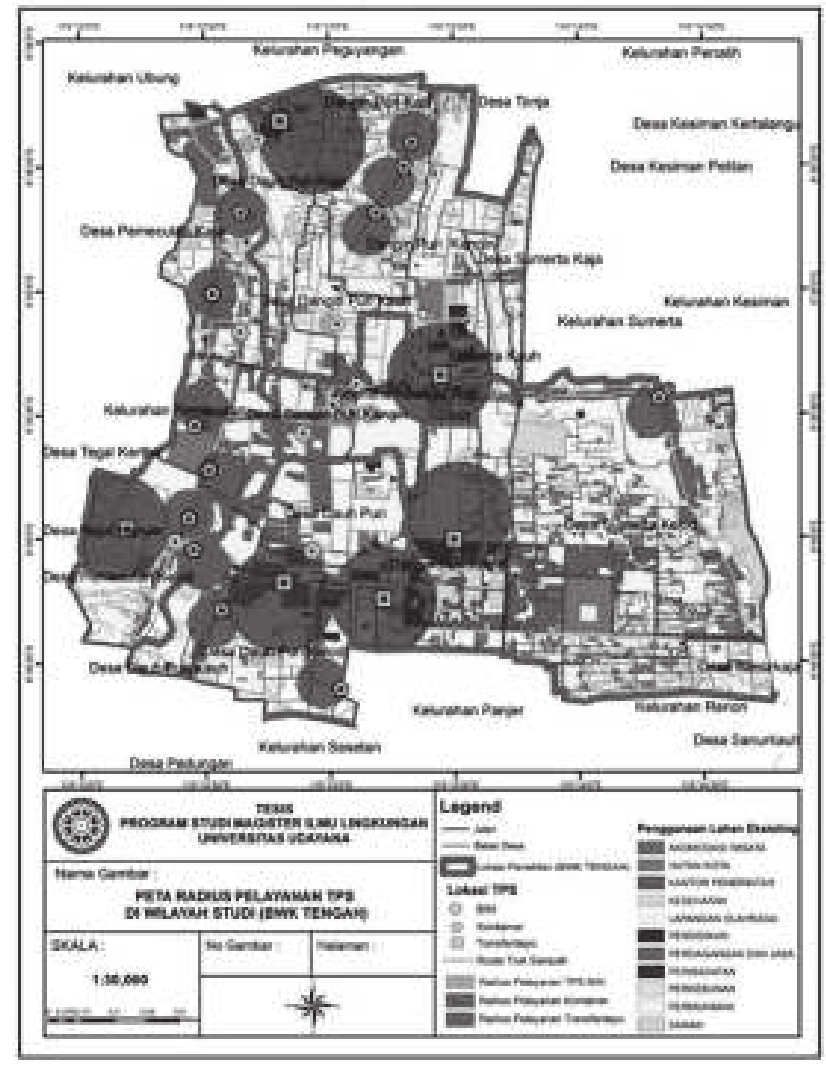

Gambar 3. Peta Radius Pelayanan TPS di Wilayah Studi (BWK Tengah)

Tabel 3. Kondisi Eksisting TPS Terhadap Faktor - Faktor Analisis Tapak

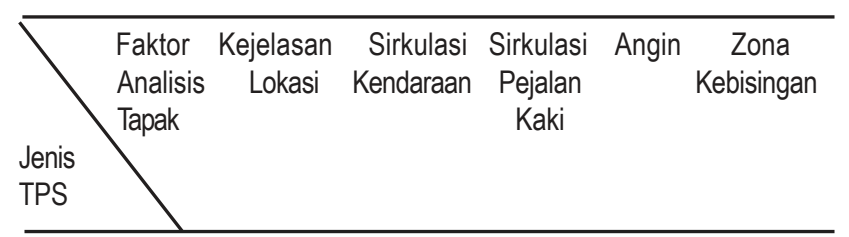

TPS Tipe BIN TPS Tipa Kontainer $\sqrt{ }$ TPS Tpe Transferdepo $\sqrt{ }$

\section{Analisis Penilaian Resiko Kerusakan Lingkungan Pada Lokasi TPS}

Analisis penilaian resiko dilakukan atas dasar identifikasi dan perkiraan resiko diperoleh dari hasil kuisioner yang diberikan kepada pada pakar, akademisi dan masyarakat.

- Matriks Peluang Resiko Berdasarkan Penilaian Masyarakat

Berdasarkan hasil penilaian masyarakat tentang peluang resiko dan besaran resiko yang mungkin terjadi dari kegiatan TPS didapatkan sebagai berikut :
1. TPS bersiko tinggi untuk mencemari air tanah

2. TPS bersiko tinggi untuk mencemari sumber air bersih (air permukaan)

3. TPS bersiko tinggi untuk mencemari udara dan bau

4. TPS bersiko tinggi untuk merusak keindahan kota, dan

5. TPS berisko tinggi untuk meningkatkan penyakit di masyarakat

- Matriks Peluang Resiko Berdasarkan Penilaian Pakar/Praktisi

Berdasarkan hasil penilaian pakar/praktisi tentang peluang resiko dan besaran resiko yang mungkin terjadi dari kegiatan TPS didapatkan sebagai berikut :

1. TPS bersiko tinggi untuk mencemari udara dan bau

2. TPS bersiko tinggi untuk merubah tata guna lahan.

\subsubsection{Keterkaitan Aspek Teknis dan Lingkungan Dalam Penentuan Lokasi TPS}

Hasil analisis dari kedua aspek ini menunjukan kesamaan terkait penentuan lokasi dan kriteria bangunan TPS, dalam SNI dan perencanaan Tapak disebutkan bahwa TPS harus dekat dengan sumber sampah dan mudah dijangkau. Hal lain yang perlu diperhatikan adalah akses yang mudah dicapai agar mempersingkat waktu pengangkutan, selain itu memberikan rasa aman bagi pejalan kai untuk mencapai TPS.

Struktur bangunan yang disebutkan dalam SNI adalah harus kedap air, sedangkan dalam perencanaan tapak disebutkan bahwa bangunan harus kedap udara. Keduanya memiliki kesamaan, yakni memberikan perlindungan dan kenyamanan bagi penduduk yang tinggal disekitar TPS.

\subsection{Analisis Aspek Teknis Sebaran dan Kebutuhan Lokasi TPS}

\subsubsection{Strategi Pengembangan TPS Melalui Analisis SWOT}

Berdasarkan pemetaan analisis SWOT diatas, maka alternative strategi yang dihasilkan adalah strategi SO (Strength. Opportunity) lebih jelas sebagai berikut :

\section{Strategi SO}

1. Tupoksi yang sudah dimiliki Dinas Kebersihan dan Pertamanan Kota Denpasar, hendaknya dimanfaatkan dan dilaksanakan oleh para pegawainya sebagai acuan untuk melaksanakan tugas. 
2. Berdasarkan Renstra pada Dinas Kebersihan dan Pertamanan Kota Denpasar, jumlah pegawai yang ada di bidang persampahan masih dirasa mencukupi hal ini dapat dilihat dari terangkutnya sampah di TPS setiap hari.

3. Peraturan Daerah tentang Pengelolaan sampah telah mengatur ketentuan terkait lokasi TPS, salah satunya adalah dekat dengan kawasan permukiman agar mudah dijangkau oleh masyarakat.

4. Mengoptimalkan peran Dinas Kebersihan dan Pertamanan Kota Denpasar dalam pengelolaan persampahan. Termasuk mengatur jumlah TPS dan penentuan lokasi TPS yang ideal untuk diterapkan di Kota Denpasar sesuai dengan Peraturan Daerah No. 27 tahun 2011 tentang RTRW.

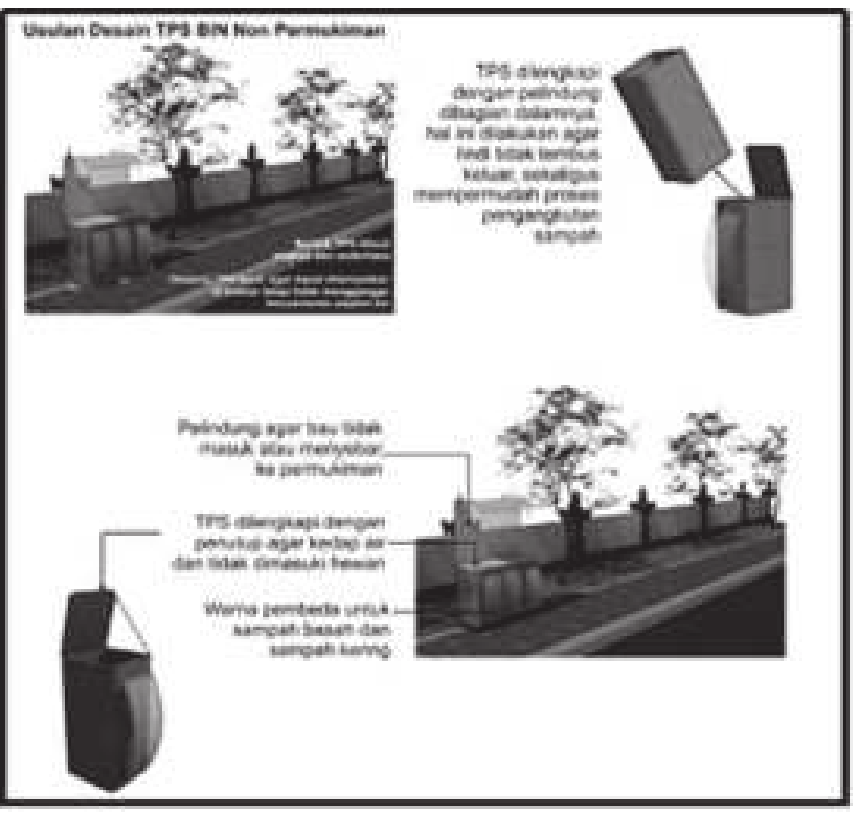

(a)

Gambar 4. (a) Usulan Perubahan Bentuk TPS BIN Non Permukiman

(b) Rekomendasi TPS BIN Permukiman Dengan Model Desain Trotoar

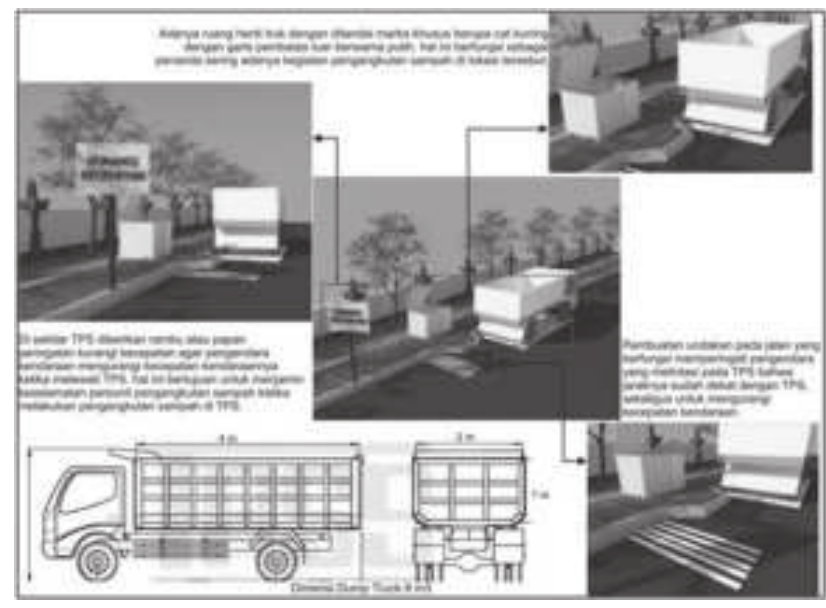

Gambar 5. Alternatif pada Pemenuhan Kebutuhan Ruang Untuk TPS Bin Permukiman
3.5. Rekomendasi Penentuan Kebutuhan Lahan dan Lokasi TPS di Kota Denpasar (BWK Tengah)

A. Rekomendasi Aspek Teknis

Rekomendasi yang diberikan untuk tempat penampungan sampah dilihat dari bentuknya antara lain :

- TPS jenis BIN dirubah bentuknya dengan dua macam TPS BIN yaitu TPS BIN permukiman dan TPS BIN perdagangan, ruang terbuka hijau dan ruang publik lainya.

TPS jenis kontainer harus memiliki area manuver truk dan memiliki landasan.

- TPS Transferdepo di wilayah penelitian banyak dalam keadaan rusak tidak dilengkapi dengan sistem penampungan lindi, perlunya perbaikan dan penyempurnaan sarana penunjang untuk TPS transferdepo.

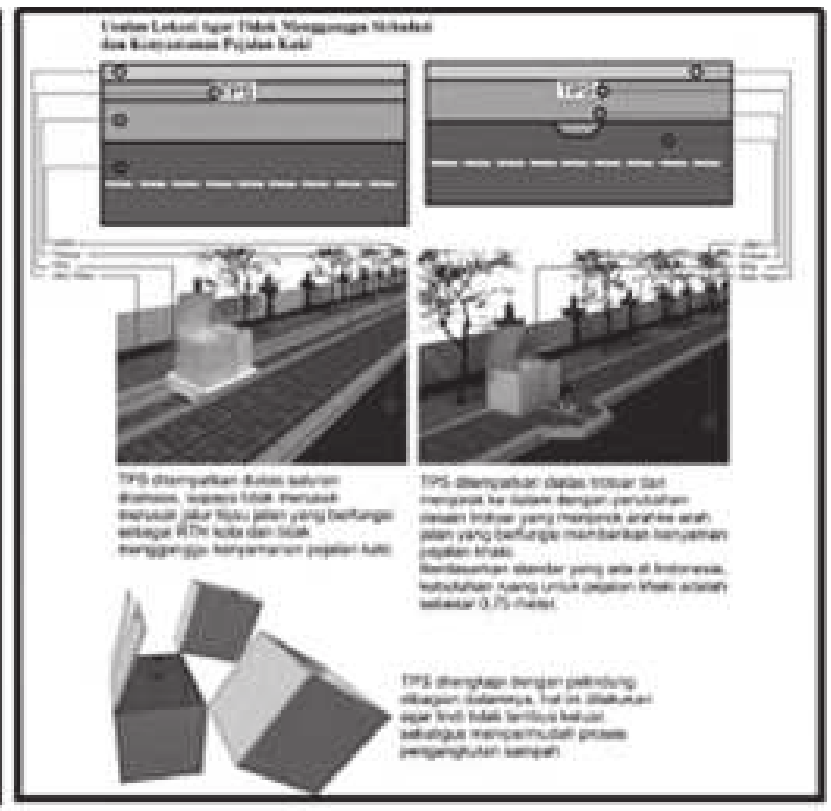

(b)

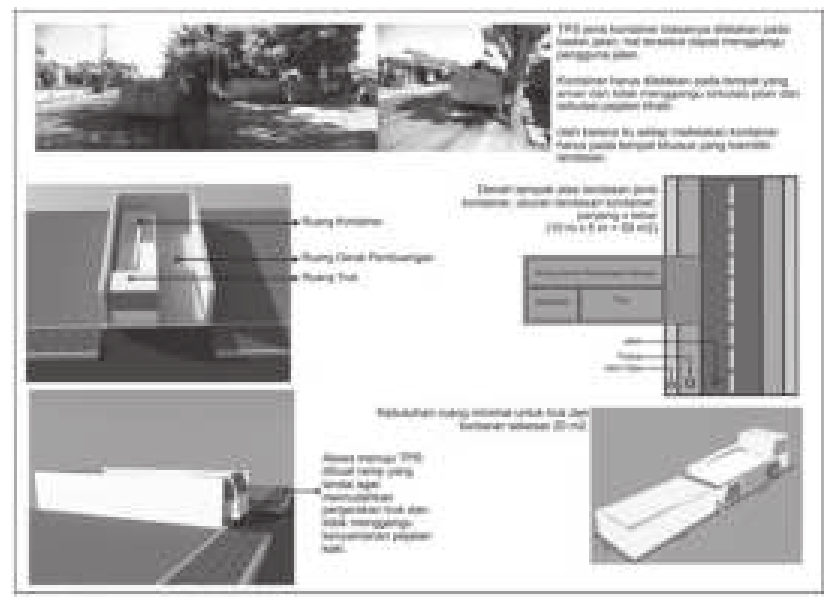

Gambar 6. Rekomendasi Pemenuhan Kebutuhan Ruang Untuk TPS Kontainer 


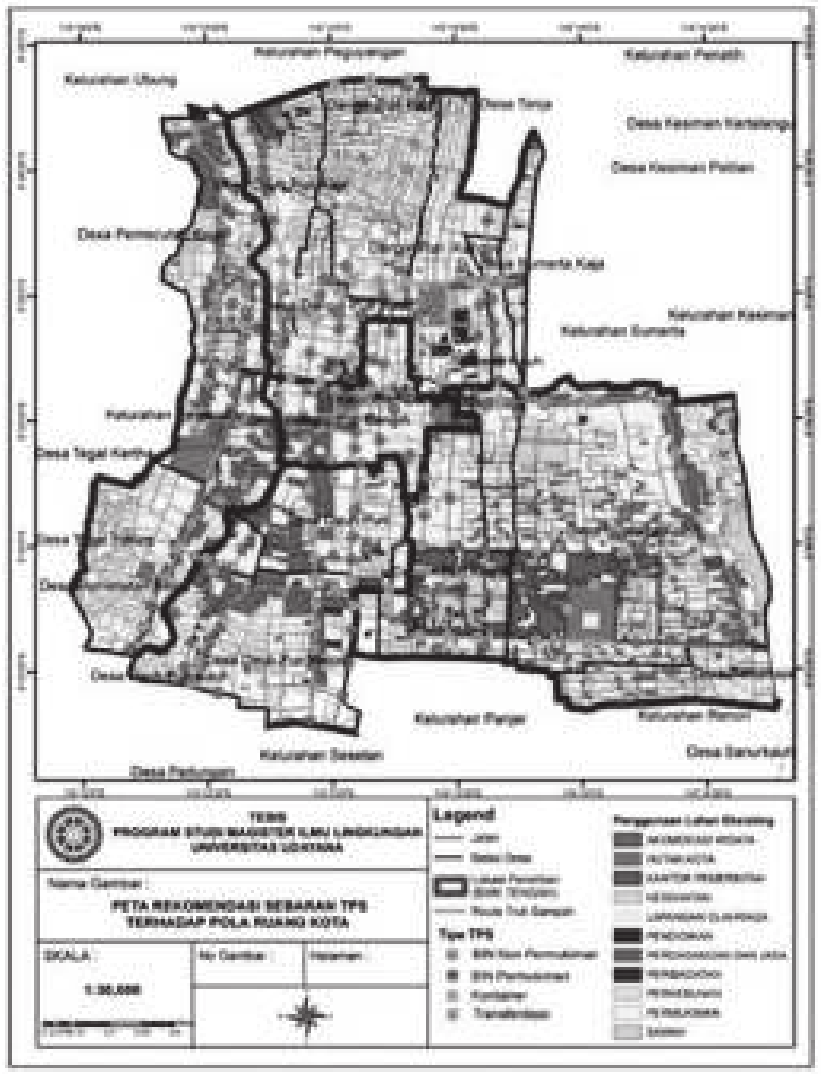

Gambar 7. Peta Rekomendasi Sebaran TPS Terhadap Pola Ruang di BWK Tengah

\section{SIMPLUAN DAN SARAN}

\subsection{Simpulan}

1. Kondisi TPS di wilayah studi banyak dalam keadaan rusak dan daya tampung untuk TPS BIN, Kontainer dan Transferdepo sudah tidak mencukupi untuk menampung sampah yang dihasilkan oleh masyarakat, serta berdasarkan evaluasi pada setiap jenis TPS yang ada di lokasi studi belum memenuhi standar dalam SNI. Kebututuhan TPS ideal pada tahun 2014 adalah 191 unit (TPS BIN Non Permukiman 85 unit, TPS BIN Permukiman 69 unit, TPS Kontainer 32 unit dan Transferdepo 5 unit) dan pada tahun 2019 adalah 394 unit (TPS BIN Non Permukiman 182 unit, TPS BIN Permukiman 162 unit, TPS Kontainer 45 unit dan Transferdepo 5 unit). Kebutuhan lahan TPS pada tahun 2014 dengan memperhitungkan dimensi truk kebutuhan lahan $1049 \mathrm{~m}^{2}$ atau setara dengan 0,1049 hektar, sedangkan pada tahun 2019 sebesar $6452 \mathrm{~m}^{2}$ atau setara dengan 0,645 hektar.

2. Pendapat masyarakat terhadap kriteria penentuan lokasi TPS relatif selaras dengan aspek teknis berdasarkan kajian literature penelitian ini, yaitu keinginan masyarakat tentang lokasi TPS yang berjarak $251-500 \mathrm{~m}$ dari timbulan sampah, $0-50 \mathrm{~m}$ dari rute pengangkutan sampah dan lokasinya berada pada lahan kosong. Pola perilaku masyarakat yang membuang sampah sembarangan pada lahan kosong akibat tidak tersedianya TPS atau jangkaun pelayanan TPS yang jauh disebabkan karena, kondisi fisik lingkungan khususnya permukiman padat dan tidak tertata dengan baik sehingga dalam penyediaan sarana pewadahan dan pengangkutan sampah menjadi sulit karena membutuhkan lahan yang tidak tersedia pada kawasan pemukiman padat. Selain itu mekanisme kontrol dalam pelaksanaan PERDA No 3 tahun 2000 tentang kebersihan dan ketertiban umum.

3. Berdasarakan hasil analisis strategi dalam terkait dalam penentuan lokasi dan kebutuhan lahan TPS didapatkan rekomendasi sebagai berikut :

- Penentuan lokasi TPS didasarkan pada kebutuhan jenis TPS terhadap pola ruang kawasan. Pertimbangan lain yang dijadikan dasar penentuan lokasi TPS adalah ketersedian lahan yang ada di kawasan tersebut.

- Bentuk TPS harus sesuai standar yang ada pada SNI dimana pada ketentuan SNI dan faktor keamanan lingkungan menyebutkan bahwa harus mudah dijangkau, kedap air dan tidak menimbulkan bau.Rekomendasi yang diberikan untuk tempat penampungan sampah dilihat dari bentuknya antara lain:

a. TPS jenis BIN dirubah bentuknya dengan dua macam yaitu TPS BIN permukiman dan TPS BIN perdagangan, ruang terbuka hijau dan ruang publik lainya (non permukiman).

b. TPS jenis kontainer harus memiliki area manuver truk dan memiliki landasan.

c. TPS Transferdepo diwilayah penelitian banyak dalam keadaan rusak tidak dilengkapi dengan sistem penampungan lindi, perlunya perbaikan dan penyempurnaan sarana penunjang untuk TPS transferdepo

\subsection{Saran}

1. Penentuan lokasi TPS perlu mempertimbangkan kriteria aspek lingkungan yaitu analisis tapak di sekitar lokasi rencana peletakan TPS.

2. Rekomendasi untuk mengurangi dampak yang akan timbul dari adanya kegiatan di TPS:

Rekomendasi yang diberikan untuk mengurangi dampak pada pencemaran air tanah dan sumber air, salah satunya adalah dengan membuat penampungan lindi di TPS.

Rekomendasi yang diberikan untuk mengurangi dampak pencemaran udara, rusaknya keindahan kota dan 
meningkatnya penyakit di masyarakat salah satu upayanya adalah dengan memberikan penutup pada TPS, cara lain dengan menambahkan tanaman/vegetasi di sekeliling TPS.

Rekomendasi yang diberikan untuk mencegah adanya perubahan tata guna lahan di sekitar TPS, salah satu cara adalah dengan menerapkan peratuarn zonasi atau zoning regulation yang ketat.

3. Optimalisasi peran DKP Kota Denpasar dalam pengelolaan persampahan khususnya pada TPS dengan meningkatkan program sosialisasi dan pembinaan masyarakat dalam pengelolaan khususnya pemanfaatan kembali sampah di lingkungannya.

4. Perlu adanya mekanisme kontrol masyarakat dalam penerapan PERDA No 3 tahun 2000 tentang kebersihan dan ketertiban umum. dengan pemanfaatan lembaga formal atau non formal dalam melakukan kontrol sosial di masyarakat tentang pengelolaan sampah khususnya sebagai pengawasan atau pelaksana PERDA No 3 tentang kebersihan dan ketertiban umum yang mengatur dalam pembuangan sampah.

\section{DAFAR PUSTAKA}

Anonim. 2011. Rencana Tata Ruang Kota Denpasar.

Anonim. 2002. SNI 19-2454-2002 Tentang Tata Cara Teknik Operasional Pengelolaan Sampah Perkotaan. Badan Standarisasi Nasional.

Azwar, Azrul. 1990. Pengantar Ilmu Lingkungan. Jakarta : Mutiara Sumber Widya

Darmasetiawan M. 2004. Sampah dan Sistem Pengelolaanya. Ekamitra Engineering. Jakarta.
Destanto, Kukuh. 2004. “Studi Persepsi Masyarakat terhadap Tingkat Kepentingan Penyediaan Ruang Terbuka Publik (RTP) yang Aksessibel bagi Masyarakat Difabel (Studi Kasus : AlunAlun Utara Solo)"(skripsi). Program Studi Pembangunan Wilayah dan Kota, Fakultas Teknik, Universitas Diponegoro, Semarang.

George Tchobanoglous, Hillary Thiesen and Rolf Eliassen. 1997. Solid Waste. McGRAW-Hill. Kogahusha.

George Tchobanoglous, Hillary Thiesen and Samuel A. Vigil. 1993. Integrated Solid Waste. McGRAW-Hill. Kogahusha.

Kodoatie, R. J. dan Sjarief, R. 2005. Pengelolaan Sumber Daya Air Terpadu. ANDI. Yogyakarta

Koppleman, Lee dan de Chiara, Joseph. 1978. Standar Perencanaan Tapak. Erlangga. Jakarta.

Sub Direktorat Pengelolaan dan Pengusahaan. Direktorat Pengembangan Penyehatan Lingkungan Pemukiman. Direktorat Jendral Cipta Karya. Departemen Pekerjaan Umum. 2006. Pengelolaan Sampah dan Air Limbah Berbasis Masyarakat. Bekasi.

Sub Direktorat Pengelolaan dan Pengusahaan. Direktorat Pengembangan Penyehatan Lingkungan Pemukiman. Direktorat Jendral Cipta Karya. Departemen Pekerjaan Umum. 2006. Perencanaan Prasarana dan Sarana Pengumpulan dan Pengangkutan Sampah. Bekasi.

Zula'aiddin, Muhammad dan Warmadewanti, I D A A. 2010. Kajian Peningkatan Umum Pakai TPA dan Pemanfaatan sampah di Kecamatan Tanah Grogot Kabupaten Paser Propinis Kalimantan Timur. Prosiding Seminar Nasional Manajamen Teknologi XI. Surabaya 6 Pebruari. 